\title{
ENSAIO TEÓRICO SOBRE OS VIESES COGNITIVOS NOS JULGAMENTOS DOS PREPARADORES DAS DEMONSTRAÇÕES CONTÁBEIS
}

\section{THEORETICAL ESSAY ON THE COGNITIVE BIASES IN JUDGMENTS OF FINANCIAL STATEMENT PREPARERS}

\author{
PAULO VITOR SOUZA DE SOUZA \\ Universidade Federal do Pará e Universidade de Brasília. Endereço: Rua \\ Augusto Correa, 1 | Guamá | 66075-110| Belém/PA | Brasil. \\ (1) http://orcid.org/0000-0001-5746-1746 \\ paulosouzx@gmail.com
}

\section{JORGE KATSUMI NIYAMA}

Universidade de Brasília. Endereço: Campus Darcy Ribeiro - Prédio da FACE, S/N | Asa Norte | 70910-900| Brasília/DF | Brasil. (D)http://orcid.org/0000-0002-8738-3838 jorgekatsumi@gmail.com

\section{CÉSAR AUGUSTO TIBÚRCIO SILVA}

Universidade de Brasília. Endereço: Campus Darcy Ribeiro - Prédio da FACE, Sala A1-112, S/N | Asa Norte | 70910-900 | Brasília/DF | Brasil. (D)http://orcid.org/0000-0002-5717-9502 cesartiburcio@unb.br

\section{RESUMO}

Para o desenvolvimento da teoria contábil, é importante identificar e discutir aspectos comportamentais que podem influenciar o processo de julgamento e de tomada de decisão dos preparadores das demonstrações contábeis. O estudo caracteriza-se como ensaio teórico, pois aborda os efeitos cognitivos que podem afetar esse processo. A principal contribuição deste método consiste em considerar de forma conjunta peças teóricas separadas e contemplar uma perspectiva integrativa. Diversas práticas contábeis podem gerar vieses cognitivos, porém nesse ensaio serão tratados somente vieses advindos de práticas que permitem julgamentos, desconsiderando aquelas não provenientes do comportamento desses profissionais. São efeitos cognitivos que podem afetar o comportamento dos preparadores: impulsividade, ausência de ceticismo, otimismo natural e pessimismo, familiaridade, ajuste heurístico, excesso de confiança, aversão à perda, aversão à mudança e complexidade da tarefa. Estes aspectos podem ocasionar a falta de comparabilidade nos julgamentos realizados pelos indivíduos, mediante julgamentos que diferem de acordo com traços de personalidade dos decisores. A reflexão acerca da discussão desses aspectos comportamentais aplicados à contabilidade contribui para o desenvolvimento da contabilidade como ciência, por meio da integração da psicologia à ciência contábil. Para esses aspectos, elaboram-se questões que podem ser adotadas em estudos futuros, por meio da realização de semiexperimentos com profissionais contábeis.

Palavras-chave: Contabilidade Comportamental. Teoria Contábil. IFRS. Efeitos Cognitivos. 


\begin{abstract}
For the development of accounting theory, it is important to identify and discuss behavioral aspects that may influence the judgment and decision-making process of financial statement preparers. The study is characterized as a theoretical essay, as it addresses the cognitive effects that can affect this process. The main contribution of this method is to jointly consider separate theoretical pieces and to contemplate an integrative perspective. Several accounting practices can generate cognitive biases, however, in this essay, only the biases arising from practices that allow these judgments will be dealt with, disregarding those not arising from the behavior of these professionals. These are cognitive effects that can affect the behavior of preparers: impulsiveness, lack of skepticism, natural optimism and pessimism, familiarity, adjustment heuristic, overconfidence, loss aversion, change aversion and task complexity. These aspects may lead to a lack of comparability in judgments made by individuals through judgments that differ according to the personality traits of the decision makers. Reflection on the discussion of these behavioral aspects applied to accounting contributes to the development of accounting as a science by integrating psychology with accounting science. For these aspects, questions are elaborated that can be adopted in future studies, by conducting semi-experiments with accounting professionals.
\end{abstract}

Keywords: Behavioral Accounting. Accounting Theory. IFRS. Cognitive Effects.

\title{
1 INTRODUÇÃO
}

A ciência contábil consiste em um processo sistemático de fornecimento de informações sobre a riqueza e os efeitos de eventos econômicos no patrimônio de uma entidade. Esse processo é composto por métodos, regras e procedimentos que podem diferir entre participantes em determinados eventos econômicos (Bruns, 1968).

Um trabalho importante com que os profissionais deparam ao longo da sua atuação consiste na tomada de decisão, processo caracterizado pela interação entre: informações, as quais são disponíveis aos indivíduos; percepções, mediante enquadramento de problemas; julgamento, por meio de análises das informações e problemas; e escolha da decisão, com base nos três conceitos anteriores (Ishaque, 2020).

Bruns (1968, p. 469) afirma que "sabe-se relativamente pouco sobre o modo como a informação é usada na tomada de decisões e, sem esse conhecimento, é difícil prever os diversos efeitos que diferentes sistemas de contabilidade ou informações terão sobre as decisões". A tomada de decisão compreende um trabalho difícil e arriscado, pois más decisões podem danificar um negócio, e por vezes causam danos irreparáveis (Hammond, Keeney \& Raiffa, 1998). Assim, Feldman, Kutscher e Yay (2020) comentam que assimetrias, percepções, emoções, preferências, escolhas e o próprio comportamento do indivíduo afetam os julgamentos e decisões, resultando assim em diferentes avaliações a um mesmo evento.

É importante compreender o processo de julgamento dos preparadores das demonstrações contábeis porque eles estabelecem a confiabilidade inicial das informações contábeis que serão utilizadas posteriormente pelos demais usuários internos e externos (Clor-Proell \& Maines, 2014). Assim, além de estabelecer confiabilidade inicial, é relevante compreender o processo de julgamento do preparador dessas demonstrações pelo ineditismo dessa abordagem. Normalmente trabalhos que abordam os vieses cognitivos tratam do tomador de decisão e baseiam-se em informações de demonstrativos já finalizados, portanto entender os vieses cognitivos que influenciam a elaboração dos demonstrativos contribui para uma ampla gama de usuários que utilizam as demonstrações para suas decisões.

Para Bonner (1999), os julgamentos realizados pelos diversos usuários da informação tendem a tomar a forma de previsões sobre o futuro ou uma avaliação de um estado atual de 
coisas. Assim, de modo geral, os eventos futuros reportados pela contabilidade utilizam expressões de incerteza, cujo uso, porém, pode influenciar o comportamento do tomador de decisões, com possíveis impactos nos relatórios financeiros (Zhang, Zoysa \& Cortese, 2019).

Clor-Proell e Nelson (2007, p. 700) comentam que o International Accounting Standards Board (IASB) "[...] tem defendido a mudança para um sistema de relatório financeiro mais "baseado em princípios" que evita regras e exige julgamento mais profissional para determinar a contabilidade mais adequada". Como as International Financial Reporting Standards (IFRS) são baseadas em princípios, elas contêm "expressões de incerteza" que denotam níveis de probabilidade ao prescrever eventos (Chand, Cummings \& Patel, 2012).

Devido à natureza subjetiva e ao aumento do uso de julgamento profissional, com base nas normas baseadas em princípios, vieses comportamentais podem surgir, prejudicando a capacidade dos contadores na escolha de um tratamento que melhor reflete o evento contábil (Perera, Chand \& Mala, 2019). Portanto, analisar os vieses nas decisões dos preparadores possui uma abordagem distinta dos demais usuários da informação porque estes estão delimitados pelo uso e aplicação das normas IFRS.

A aplicação de normas contábeis que incluem expressões de incerteza envolve um julgamento considerável dos indivíduos (Doupnik \& Riccio, 2006), que causa diferentes interpretações, prejudicando a credibilidade do processo de convergência e impedindo a comparabilidade dos relatórios financeiros (Chand et al., 2012). Assim, quando os preparadores tomam decisões com base em expressões de incerteza, uma possível ambiguidade na interpretação desses termos afeta o processo de tomada de decisão (Han, Chand \& Mala, 2019).

Nos últimos anos surgiu um novo campo da ciência comportamental, que tem como foco os problemas dos indivíduos no modo como pesquisam, codificam, ponderam e combinam informações para formar julgamentos e tomar decisões (Einhorn, 1976). Esse campo, que está na intersecção entre a psicologia, economia, estatística e administração, tornou-se relevante para a área de negócios, tais como a contabilidade, marketing e finanças (Einhorn, 1976).

Em 1966, o American Accounting Association (AAA) desenvolveu um statement intitulado "A Statement of Basic Accounting Theory" (ASOBAT), o qual, dentre vários objetivos, buscou discutir a possível natureza, escopo e estrutura da teoria contábil no futuro. O ASOBAT apontou que uma das principais áreas de pesquisa em que estão ocorrendo mudanças é a do conhecimento do comportamento humano e sugeriu que o estudo da contabilidade poderia incluir pesquisas sobre os aspectos comportamentais (AAA, 1966). Portanto, uma área de pesquisa que pode contribuir para o desenvolvimento da estrutura da teoria contábil é a do impacto da informação contábil nas ações humanas (AAA, 1966).

Assim, as pesquisas em contabilidade comportamental é um dos temas mais abordados atualmente. Trotman, Tan e Ang (2011) comentam que este campo se preocupa com o comportamento dos participantes das organizações, a influência de informações contábeis sobre os usuários e a compreensão dos julgamentos dos próprios preparadores das demonstrações contábeis.

Para Bruns (1968), as relações cognitivas cujas informações são relevantes para as decisões são potencialmente importantes para o desenvolvimento da teoria contábil e para o projeto de decisão da informação. Assim, compreender o comportamento, por meio dos impactos das informações contábeis no julgamento e tomada de decisão dos usuários, torna-se relevante para o desenvolvimento da teoria da contabilidade.

Conforme exposto, é importante identificar quais características do comportamento podem ser influenciadas por informações reportadas pela contabilidade. Portanto, este artigo tem como objetivo identificar e discutir os aspectos comportamentais que podem gerar vieses nos julgamentos e decisões dos preparadores das demonstrações com base nas normas internacionais de contabilidade.

Ressalta-se que a análise dos vieses cognitivos cabe somente em algumas práticas contábeis, pois existem práticas que não permitem julgamento profissional, isto é, que não são 
discricionárias, como, por exemplo, o pagamento de uma duplicata. Este estudo desconsidera também práticas contábeis advindas de pressões externas que o profissional sofre na preparação das demonstrações, pois, mesmo que elas influenciem seus julgamentos, este trabalho analisa aquelas advindas do comportamento, que relacionam-se à informação contábil. Como exemplo, pressões que o profissional sofre de seus superiores geram vieses na elaboração de um demonstrativo, porém esses vieses não são advindos de seu comportamento. Já a discricionariedade em procedimentos contábeis permite julgamentos enviesados, e esses vieses advêm de aspectos comportamentais. Por exemplo, as práticas relacionadas aos accruals, que são os ajustes advindos de regime de competência, são as típicas operações que carregam um elevado grau de subjetividade.

Deve-se compreender os aspectos do comportamento humano mais influenciados pelas informações contábeis, visando identificar possíveis vieses que distorcem os julgamentos dos indivíduos. Assim, a relevância do estudo se apresenta por meio da evidenciação do que vem sendo apontado como as principais "falhas" dos julgamentos e decisões tomadas pelos usuários que geram e utilizam informações contábeis, em decorrência das idiossincrasias desses profissionais. Portanto, este estudo visa contribuir para a literatura e para os usuários da informação ao fornecer um quadro sobre aspectos intrínsecos ao comportamento humano que podem afetar negativamente a geração de informações contábeis, afetando a confiabilidade e utilidade dessas para diversos usuários.

\section{ASPECTOS ESTRUTURAIS DO ENSAIO}

A presente pesquisa caracteriza-se como um ensaio teórico, pois visa discutir as características comportamentais (efeitos cognitivos) que mais influenciam o processo de julgamento de tomada de decisão dos usuários das informações prestadas pela contabilidade, tendo como base estudos desenvolvidos na área comportamental.

Um ensaio teórico não exige comprovação empírica baseada em evidências, ou seja, a utilização de dados estatísticos ou outros métodos tradicionais de coleta de dados não são relevantes para este tipo de pesquisa (Meneghetti, 2011). Ao invés disso, sua principal contribuição consiste em considerar de forma conjunta várias peças teóricas separadas e contemplar uma perspectiva integrativa (Sena, 2009).

Meneghetti (2011, p. 322) comenta que a força do ensaio teórico não está atrelada ao rigor metodológico da pesquisa, mas sim "[...] na capacidade reflexiva para compreender a realidade". Ou seja, um ensaio apresenta integração de várias obras distintas e nessa integração visa apresentar uma discussão que ajude o indivíduo a compreender a realidade.

Assim, busca contribuir por meio da apresentação de uma nova perspectiva conceitual, baseada em um aparato qualitativo-analítico, ou seja, o colabora para os estudos científicos ao utilizar o suporte teórico para conceber uma perspectiva qualitativa alternativa para a literatura (Sena, 2009).

Conforme Barney (2001), a parte mais difícil na elaboração de um ensaio teórico talvez seja o posicionamento de um argumento relativo à literatura percebida por parte do pesquisador. Portanto, Barney (2001, p. 643) comenta que não há uma maneira melhor para posicionar um ensaio teórico, por conta da subjetividade da seleção do pesquisador pelo objeto pesquisado, "[...] e qualquer que seja a escolha feita em relação posicionamento envolve necessariamente enfatizar algumas percepções à custa de outras".

Por fim, no ensaio teórico a orientação da pesquisa não é dada necessariamente pela busca de respostas e afirmações verdadeiras, mas pelo delineamento de perguntas que orientem os sujeitos para reflexões mais profundas (Meneghetti, 2011). Sendo assim, no corpo do ensaio teórico, para cada conceito ou teoria apresentados, serão delineadas questões relacionadas. 


\section{CORPO DO ENSAIO TEÓRICO}

\subsection{Usuários da informação contábil, julgamento e tomada de decisão}

A contabilidade tem como objetivo gerar informações para apoiar o processo de julgamento e tomada de decisão de usuários internos e externos. Assim, como a informação contábil é determinada em parte por um sistema contábil, uma classificação dos tomadores de decisão fornece insights sobre o efeito que as informações contábeis podem ter no conjunto de decisões selecionado por eles (Bruns, 1968).

Julgamentos e decisões que utilizam as informações contábeis são feitos por quatro grandes grupos: auditores, pois todo o processo de auditoria é permeado por julgamentos profissionais baseados em normas contábeis internacionais; preparadores das demonstrações, já que estes fazem julgamentos sobre o que incluir nos relatórios; usuários externos das demonstrações, os quais fazem julgamentos sobre futuros resultados e fluxos de caixa futuros; e, por fim, gestores, que utilizam relatórios financeiros para decisões de planejamento, avaliação, desempenho e alocação de recursos (Trotman et al., 2011).

Conforme aponta o CPC 00 (R2), os usuários externos, aos quais se destinam os relatórios financeiros, são compreendidos como: "[...] investidores, credores por empréstimos e outros credores, existentes e potenciais [...]", os quais não podem “[...] exigir que as entidades que reportam forneçam informações diretamente a eles” (CPC, 2019, p. 5). Esses são considerados como os principais usuários dos relatórios contábeis, elaborados pelos profissionais da contabilidade, considerados como usuários internos.

Portanto, cada um desses grupos de usuários pode afetar a empresa e as suas operações, na medida em que as informações contábeis são utilizadas como parte do processo de decisão. No entanto, os objetivos dos usuários externos e internos podem diferir, tornando assim a análise dos efeitos da informação contábil sobre as diversas classes de tomadores de decisão uma tarefa difícil de compreender (Bruns, 1968).

Chand et al. (2012) afirmam que é improvável que cada indivíduo tenha as mesmas experiências, o que leva julgamentos e decisões a variarem. Por este motivo, as análises acerca dos aspectos comportamentais que influenciam as decisões dos usuários da informação contábil serão feitas especificamente para os preparadores das demonstrações contábeis, pois estes estabelecem a confiabilidade inicial das informações contábeis que serão utilizadas pelos demais usuários (Clor-Proell \& Maines, 2014).

Bruns (1968, p. 471) comenta que as decisões afetam eventos futuros, pois as ações futuras são determinadas a partir do momento em que uma decisão é tomada. Assim, o interesse no entendimento do comportamento do indivíduo na sua tomada de decisão é relevante, pois uma grande parte da contabilidade trata da avaliação de informações, da formação de julgamentos e da tomada de decisões com base em julgamentos, os quais por vezes estão relacionadas a eventos futuros (Einhorn, 1976).

Torna-se importante diferenciar o julgamento da tomada de decisão, para uma melhor compreensão. Bonner (1999, p. 385) define julgamento como a "[...] formação de uma ideia, opinião ou estimativa sobre um objeto, um evento, um estado ou outro tipo de fenômeno", enquanto a tomada de decisão "[...] refere-se a pensar na questão e tomar uma atitude", ou seja, os julgamentos refletem as crenças do indivíduo e as decisões se referem tanto às crenças, quanto às atitudes.

\subsection{Julgamento dos preparadores com base em padrões contábeis internacionais}

O IASB tem defendido a mudança para um sistema de relatório financeiro mais baseado em princípios, minimizando o uso de regras e exigindo um julgamento mais profissional para determinar um nível de reconhecimento e mensuração mais adequados (Clor-Proell \& Nelson, 2007). Assim, como as normas IFRS são baseadas em princípios, “[...] o julgamento profissional 
é importante e o desejo de um relatório imparcial é primordial" (Chand, Patel \& Patel, 2010, p. 280).

Os preparadores das demonstrações são os principais usuários das normas IFRS, pois fazem julgamentos sobre o que deve ser incluído nos relatórios financeiros, que tratamentos contábeis adotar, as estimativas utilizadas e a probabilidade de eventos futuros (Trotman et al., 2011). Assim, as normas emitidas pelo IASB exigem que esses preparadores das demonstrações apliquem adequadamente o seu julgamento sobre que tipo de informação incluir nos relatórios (Chand et al., 2010).

No entanto, Chand et al. (2010, p. 281) comentam que, se as normas "IFRS não forem aplicadas de forma consistente, então é improvável que relatórios comparáveis sejam alcançados mesmo se os países adotarem um único conjunto de padrões de relatórios financeiros globalmente aceitáveis". O que pode gerar inconsistência na aplicação das normas é a "[...] inexistência de concordância quanto ao significado numérico das expressões de incerteza contidas nas IFRS [...]", o que pode resultar em falta de comparabilidade das empresas (Chand et al., 2012, p. 156).

As IFRS possuem uma quantidade significativa de expressões de incerteza relacionadas ao reconhecimento e divulgação de itens contábeis (Zhang et al., 2019). Essas expressões de incerteza, as quais constituem limiares para o reconhecimento, mensuração ou divulgação, envolvem julgamento considerável por parte dos indivíduos, em especial dos preparadores das demonstrações (Doupnik \& Riccio, 2006).

As expressões constantes nas normas contábeis têm como função orientar os julgamentos, sendo frequentemente usadas para denotar níveis de probabilidade ao prescrever o reconhecimento, mensuração e divulgação de eventos (Chand et al., 2012). Porém o uso dessas expressões pode ter consequências não intencionais para a manipulação de informações, pois as pessoas interpretam expressões de incerteza de maneiras distintas e os preparadores podem tirar proveito da ambiguidade para disfarçar riscos e resultados adversos (Zhang et al., 2019).

Almeida, Lemes, Weffort e Malaquias (2008), ao investigarem se diferentes usuários apresentam percepções distintas em relação a expressões de incerteza elencadas em normas de contabilidade aplicadas no Brasil, concluem que as percepções são diferentes para os diversos tipos de usuário da informação e essas expressões têm potencial de interpretações variadas, o que consequentemente pode distorcer a elaboração e interpretação das demonstrações e relatórios contábeis, interferindo assim na tomada de decisão dos demais usuários. Portanto, essa divergência de interpretações de um mesmo termo pode ter consequências negativas por conta de julgamentos distintos dos usuários (Almeida et al., 2008).

Além disso, como os indivíduos possuem objetivos diferentes, os seus julgamentos podem diferir substancialmente. Essa divergência de interesses torna a análise dos efeitos da informação contábil nos julgamentos e decisões dos usuários uma tarefa difícil (Bruns, 1968). Sendo assim, como os indivíduos não possuem as mesmas experiências, há variação em seus julgamentos (Chand et al., 2012), o que pode prejudicar o processo de comparabilidade nos relatórios financeiros, justamente por estes serem baseados em normas IFRS, que possuem essas expressões de incerteza que podem ser altamente influenciadas pelas características de cada indivíduo responsável pela produção da informação.

Portanto, mediante o exposto, padrões baseados em expressões de incerteza visam aumentar o poder de julgamento do preparador das demonstrações contábeis. Porém, ao lidar com julgamentos baseados em incerteza, este profissional pode apresentar diversas interpretações distintas que, além de gerar falta de comparabilidade em seus julgamentos, podem causar vieses cognitivos nos procedimentos adotados, distorcendo a informação reportada nas demonstrações contábeis elaboradas pelo profissional contábil. 


\subsection{Aspectos comportamentais nos julgamentos e decisões em contabilidade}

É relevante compreender os aspectos comportamentais do indivíduo que utiliza a informação contábil, já que ele é influenciado pelo tipo de informação que recebe. O documento desenvolvido pelo AAA em 1966, intitulado ASOBAT, aponta que a área de pesquisa que estuda o impacto das medidas contábeis nas ações humanas pode contribuir para o desenvolvimento da teoria contábil, pois diferentes medidas contábeis têm o poder de influenciar o raciocínio desses indivíduos (AAA, 1966).

Bruns (1968, p. 469) comenta que o entendimento das “[...] relações comportamentais sobre as quais as informações são relevantes, são potencialmente importantes para o desenvolvimento da teoria contábil e para o projeto de sistemas de decisão com base na informação contábil". Assim, um novo campo da ciência comportamental tem surgido a partir desses anos. Este campo, denominado "contabilidade comportamental", está preocupado em compreender a influência das informações contábeis nos julgamentos e decisões dos usuários internos e externos (Trotman et al., 2011).

Um exame da literatura sobre contabilidade comportamental sugere que os profissionais contábeis têm evitado o desenvolvimento de um modelo comportamental próprio, tomando emprestado um conjunto de suposições de outras áreas, como a economia (Caplan, 1966). Assim, tem sido sugerido que qualquer teoria comportamental da escolha racional deve considerar certos limites cognitivos do tomador de decisão, tais como: conhecimento limitado com respeito a possíveis alternativas e consequências; capacidade cognitiva limitada; estrutura de valores em constante mudança; e tendência para "satisfazer" os próprios desejos dos agentes ao invés de maximizar os interesses dos principais (Caplan, 1966).

Como o julgamento e a decisão dos indivíduos são baseados em uma escolha racional, estes podem apresentar equívocos em sua tomada de decisão. Caplan (1966, p. 502) comenta que o comportamento racional "[...] consiste em procurar alternativas limitadas para uma solução razoável sob condições nas quais as consequências da ação são incertas". Hammond et al. (1998) apontam que esses equívocos representam uma série de falhas na forma como os indivíduos pensam em seus julgamentos e decisões, as quais podem ser representadas por meio de heurísticas, que correspondem a equívocos sensoriais; e vieses, que retratam anomalias irracionais em nosso pensamento.

Tversky e Kahneman (1973) comentam que, quando os indivíduos precisam julgar probabilidade, geralmente baseados em expressões de incerteza, empregam heurísticas em seus julgamentos, objetivando torná-los mais simples. Essas heurísticas, utilizadas sob condições de incerteza, por vezes produzem julgamentos razoáveis, porém também levam a erros (Kahneman \& Tversky, 1973). Assim, conforme apontam Perera et al. (2019), mesmo os preparadores das demonstrações mais conscientes precisam estar preparados para os vieses ocultos aos quais todos estão suscetíveis.

Os vieses ocultos do comportamento relacionam-se ao pensamento por analogia que os seres humanos apresentam, estando relacionados a experiências "duvidosas" anteriores, que podem prejudicar suas reflexões (Reva, 2019). Com vistas a processar informações de forma eficiente, os indivíduos tendem a utilizar atalhos, porém nos dias atuais o uso destes atalhos é suscetível a vieses ocultos (por exemplo, etnia ou sexo), os quais são advindos da evolução humana e podem resultar em más decisões (Bang \& Frith, 2017).

Uma vez que o viés advindo do pensamento irracional representa equívocos na forma como um indivíduo pensa, conforme Hammond et al. (1998), este estudo visa identificar e discutir alguns efeitos cognitivos que podem gerar vieses nos julgamentos dos preparadores das demonstrações, sobre o que incluir nos relatórios financeiros das entidades, ou seja, acerca do reconhecimento, mensuração e divulgação baseados em normas IFRS. 


\subsubsection{Impulsividade}

O processo decisório é composto por dois sistemas cognitivos, denominados sistema $1 \mathrm{e}$ sistema 2. No sistema 1, o processo decisório ocorre espontaneamente e não requer ou consome muita atenção do tomador de decisão, sendo assim, esse processo é executado rapidamente; já no sistema 2, os processos mentais requerem esforço, motivação, concentração e regras de aprendizado na execução, sendo assim, o processo decisório é mais lento e reflexivo (Frederick, 2005).

Assim, Frederick (2005) desenvolveu o Teste de Reflexão Cognitiva (CRT), que tem como objetivo avaliar se um indivíduo é mais impulsivo ou reflexivo no seu processo de julgamento e na tomada de decisão. O CRT consiste em uma tarefa simples para medir a capacidade cognitiva do tomador de decisão, ou seja, se ele é impulsivo ou reflexivo em seus julgamentos (Jelihovschi, Cardoso \& Linhares, 2016). Espera-se assim que pessoas mais reflexivas apresentem "melhores" escolhas em relação a uma tarefa, enquanto pessoas mais impulsivas apresentem escolhas não tão boas assim (Frederick, 2005).

Através do exposto, as questões relacionadas a reflexividade e impulsividade propostas neste artigo podem ser apresentadas da seguinte forma:

$\mathbf{Q}_{1}$ : Os preparadores das demonstrações contábeis mais reflexivos tendem a apresentar menor viés nos seus julgamentos em relação a eventos contábeis?

Q1b: Os preparadores das demonstrações contábeis mais impulsivos tendem a apresentar maior viés nos seus julgamentos em relação a eventos contábeis?

\subsubsection{Ausência de Ceticismo}

O ceticismo profissional pode ser definido de várias maneiras, por conta da falta de entendimento comum entre os reguladores, profissionais e pesquisadores. Conforme Nolder e Kadous (2015), para os reguladores, o ceticismo profissional é definido como uma atitude que inclui uma mente questionadora e uma avaliação crítica das evidências; já para os profissionais, o ceticismo pode ser definido como atitude que representa uma boa mentalidade; e, por fim, para os pesquisadores, o ceticismo consiste em adiar o julgamento até que evidências suficientes sejam acumuladas para reduzir o risco no julgamento e tomada de decisão.

Conforme Brewster, Peecher e Solomon (2015) o ceticismo profissional pode ser exercido como um meio de melhorar a qualidade do julgamento profissional, pois o profissional possui um pensamento mais crítico em relação a sua tomada de decisão, o que reduz o risco e consequentemente pode reduzir o viés nos julgamentos realizados. Para Rasso (2015), as interpretações de alto nível estão relacionadas a um maior ceticismo profissional, que pode melhorar a qualidade do julgamento realizado.

Em uma tarefa, o ceticismo profissional pode ser medido por meio da solicitação do profissional por mais evidências para a realização do seu julgamento e posterior tomada de decisão. Assim, conforme Nolder e Kadous (2015), o ceticismo profissional representa uma atitude, que pode ter consequências positivas para a redução do viés no julgamento e na tomada de decisão de diversos usuários da contabilidade, inclusive dos preparadores que realizam julgamentos com base em informações. Sendo assim, a questão relacionada ao ceticismo profissional aplicada aos preparadores é apresentada conforme segue:

Q2: Os preparadores das demonstrações contábeis que apresentam maior ceticismo profissional tendem a apresentar menor viés nos seus julgamentos em relação a eventos contábeis?

\subsubsection{Otimismo Natural e Pessimismo}

A percepção dos indivíduos pode ser distorcida por meio do otimismo e pessimismo. Pessoas otimistas esperam que as coisas sigam o seu caminho, presumindo que coisas boas ao invés de ruins vão acontecer com elas, enquanto pessoas pessimistas acreditam que as coisas não 
vão ocorrer de sua maneira e tendem a antecipar sempre os resultados ruins (Scheier \& Carver, 1985).

O otimismo e o pessimismo consistem na inclinação que um indivíduo possui para esperar o melhor ou o pior resultado possível, podendo distorcer a realidade sobre um evento. Para Scheier, Carver e Bridges (1994), os otimistas tendem a manter expectativas positivas para eventos futuros, enquanto os pessimistas inclinam-se a manter as expectativas mais negativas para o futuro.

Assim, visando investigar os efeitos do otimismo sobre o comportamento, Scheier e Carver $(1985$, p. 232 ) criaram uma escala para medir o otimismo/pessimismo disposicional do indivíduo. O teste, chamado Life Orientation Test (LOT), avalia o favorecimento da expectativa de resultado generalizada de uma pessoa e parece "[...] possuir um nível adequado de consistência interna, confiabilidade de teste e reteste, validade convergente e discriminante para torná-lo adequado para o uso em pesquisa, quando essa medida for desejada".

Sendo assim, como pessoas otimistas tendem a atribuir expectativas positivas e pessoas pessimistas expectativas negativas, as questões de pesquisa relacionadas ao terceiro aspecto abordado neste ensaio são delineadas conforme segue:

Q3a: Os preparadores das demonstrações contábeis otimistas apresentam viés em seus julgamentos, antecipando o reconhecimento e superestimando os eventos com impacto positivo no resultado?

Q3b: Os preparadores das demonstrações contábeis pessimistas apresentam viés em seus julgamentos, postergando o reconhecimento e subestimando os eventos com impacto positivo no resultado?

\subsubsection{Familiaridade}

$\mathrm{O}$ aspecto da familiaridade é considerado um fator importante que permite que os preparadores das demonstrações contábeis interpretem e apliquem de forma consistente seus julgamentos, reduzindo a incerteza inerente ao trabalho através da introdução de novos padrões contábeis (Chand et al., 2010).

Chand et al. (2010, p. 282) comentam que "quanto melhor os contadores profissionais são treinados e quanto mais eles estão expostos a um novo padrão, maior será seu nível de familiaridade com o padrão". A interpretação e aplicação de normas contábeis conhecidas como "antigas" podem ser mais coerentes do que as normas "novas", já que os procedimentos adotados nas normas antigas são mais familiares do que os procedimentos das novas normas (Chand et al., 2010). Também, os profissionais que não estão familiarizados com o padrão contábil podem ser relutantes em exercer seu julgamento.

Por outro lado, os indivíduos menos familiarizados ou menos experientes com determinada tarefa de julgamento se comportam de maneira mais cautelosa ou avessa ao risco, em comparação com aqueles que possuem maior familiaridade com a tarefa (Chand et al., 2010).

As previsões sobre eventos futuros realizadas pelos indivíduos tendem a se basear em suas memórias sobre os eventos passados (familiares) que podem ter deixado uma forte impressão, distorcendo as previsões sobre os eventos futuros (Hammond et al., 1998).

A partir do exposto, o efeito da familiaridade nos julgamentos dos preparadores das demonstrações contábeis apresenta-se inconclusiva, visto que os autores defendem positiva ou negativamente o efeito da familiaridade no julgamento profissional. Sendo assim, duas questões referentes a este aspecto comportamental são apresentadas:

Q4a: Os preparadores das demonstrações contábeis com maior familiaridade com o padrão contábil tendem a apresentar menor viés nos seus julgamentos em relação a eventos contábeis?

Q4b: Os preparadores das demonstrações contábeis com maior familiaridade com o padrão contábil tendem a apresentar maior viés nos seus julgamentos em relação a eventos contábeis? 


\subsubsection{Heurística da Ancoragem}

Os julgamentos e decisões, por muitas vezes, são influenciados por algum valor anterior. Os indivíduos fazem estimativas, começando por um valor inicial, que é ajustado para produzir uma resposta final (Tversky \& Kahneman, 1974). O valor inicial (considerado como a âncora) "[...] pode ser sugerido pela formulação do problema ou pode ser o resultado de um cálculo parcial", sendo que os valores estimados posteriormente se inclinam aos iniciais, ou seja, os julgamentos são ancorados pelos valores iniciais (Trotman et al., 2011, p. 287).

Nos negócios, os tipos mais comuns de ancoragem são constituídos por eventos passados ou tendências. Por exemplo, um comerciante tenta projetar as vendas de determinado produto para o próximo ano, porém, em seus julgamentos, ele acaba se baseando pelo volume de vendas dos anos anteriores, ou seja, os números antigos tornam-se âncoras para as estimativas futuras (Hammond et al., 1998, p. 3). Em resumo, a ancoragem sugere que no processo decisório os julgamentos são enviesados por fatores de referência, de modo que valores passados influenciam decisões futuras.

Assim, como os preparadores das demonstrações contábeis realizam julgamentos sobre eventos futuros baseados em expressões de incerteza, a quinta questão de pesquisa é apresentada conforme segue:

Q5: Os preparadores das demonstrações contábeis que utilizam âncoras tendem a apresentar maior viés nos seus julgamentos em relação a eventos contábeis?

\subsubsection{Excesso de Confiança}

Uma descoberta especificamente relevante para finanças é que o grau de excesso de confiança varia entre os indivíduos (De Bondt \& Thaler, 1995). Um número considerável de pesquisas em finanças sugere que existem indivíduos excessivamente confiantes sobre as suas habilidades de realizar julgamentos sobre o futuro (Scott, Stumpp \& Xu, 2003).

Mesmo que em sua maioria as pessoas sejam boas em fazer estimativas e previsões sobre eventos futuros, o excesso de confiança afeta a precisão das previsões realizadas, levando a erros de julgamentos e, por sua vez, a más decisões (Hammond et al., 1998), ou seja, o excesso de confiança é considerado um viés nos julgamentos realizados.

Scott et al. (2003) definem uma pessoa superconfiante como alguém que acredita fortemente em suas próprias avaliações sobre eventos futuros. Já De Bondt e Thaler (1995) comentam que o achado mais robusto na psicologia do julgamento é que as pessoas excessivamente confiantes superestimam a confiabilidade dos seus conhecimentos, o que influencia negativamente seus julgamentos e decisões.

Se os indivíduos superestimam ou subestimam seus julgamentos com base no excesso de confiança, eles podem perder oportunidades atraentes e expor o negócio a um risco maior do que imaginam (Hammond et al., 1998). Sendo assim, indivíduos excessivamente confiantes apresentam disparidade entre a realidade e crenças nos seus julgamentos (Scott et al., 2003). Assim, a sexta questão de pesquisa relacionada ao viés do excesso de confiança pode ser apresentada conforme segue:

Q6: Os preparadores das demonstrações contábeis que apresentam excesso de confiança tendem a apresentar maior viés nos seus julgamentos em relação a eventos contábeis?

\subsubsection{Aversão à Perda}

A aversão à perda tem sido usada para explicar uma ampla gama de comportamentos econômicos dos tomadores de decisão (Tom, Fox, Trepel \& Poldrack, 2007). Esse fator implica que "[...] o impacto de uma diferença em uma dimensão é geralmente maior quando essa diferença é avaliada como uma perda do que quando a mesma diferença é avaliada como um ganho" (Tversky \& Kahneman, 1991, p. 1040). 
Kahneman, Knetsch e Thaler (1991) comentam que certa diferença entre duas opções terá maior impacto se for vista como uma diferença entre opções que apresentam desvantagens do que entre opções vantajosas. Sendo assim, os indivíduos podem apresentar aversão à perda por serem mais "[...] sensíveis à possibilidade de perder objetos ou dinheiro do que a possibilidade de ganhar os mesmos objetos ou quantia em dinheiro" (Tom et al., 2007, p. 515).

A intuição básica a respeito da aversão à perda é que as perdas (resultados abaixo do esperado) são maiores do que os ganhos (resultados acima do esperado) (Tversky \& Kahneman, 1991), fazendo com que os indivíduos apresentem julgamentos distintos para as duas operações, sendo essa característica considerada um viés nos julgamentos e decisões dos indivíduos.

Assim, o viés da aversão à perda pode refletir uma resposta assimétrica à oposição perdas versus ganhos dentro de um único sistema de informação (Tom et al., 2007), sendo que essa assimetria pode distorcer os julgamentos dos usuários da informação contábil, se eles apresentarem esse viés. Portanto, uma conclusão geral sobre a aversão à perda é que tais escolhas são melhor explicadas porque as mudanças que tornam as coisas piores têm mais efeito do que as que tornam as coisas melhores (Kahneman et al., 1991).

Através do exposto, entende-se que o viés da aversão à perda pode influenciar significativamente os julgamentos dos preparadores das demonstrações contábeis. Assim, a sétima questão de pesquisa é apresentada conforme segue:

Q7: Os preparadores das demonstrações contábeis que apresentam aversão à perda tendem a apresentar maior viés nos seus julgamentos em relação a eventos contábeis?

\subsubsection{Aversão à Mudança (Status Quo)}

Uma implicação da aversão à perda é que os indivíduos têm forte tendência a permanecer como estão, porque as desvantagens de mudar são maiores do que as vantagens. Assim, como o status quo consiste em uma consequência natural da assimetria da aversão à perda, as desvantagens de uma mudança são maiores do que suas vantagens (Kahneman et al., 1991).

O status quo representa a aversão à mudança, ou seja, não fazer nada, mantendo a decisão atual ou anterior, é quase sempre uma possibilidade (Samuelson \& Zeckhauser, 1988). O status quo é considerado um viés que influencia as escolhas feitas e representa o desejo dos indivíduos de proteger o ego contra eventuais danos causados pelas mudanças (Hammond et al., 1998).

Diante de novas opções, os tomadores de decisão por vezes seguem o status quo. Por exemplo, tendem a seguir políticas rotineiras das empresas, compram produtos das mesmas marcas, permanecem no mesmo emprego, entre outros, e mudar significa assumir riscos (Samuelson \& Zeckhauser, 1988).

Para Hammond et al. (1998), romper com o status quo significa agir e, quando o indivíduo age, ele assume a responsabilidade pelo risco. Assim, naturalmente, as pessoas procuram razões para não mudar, mantendo o status quo, que representa o curso mais seguro, evitando o risco e, consequente, perdas pelo medo da mudança.

Portanto, conforme exposto, os indivíduos apresentam naturalmente esse viés da aversão à mudança, que representa uma armadilha dentro de nossa psique, influenciando nossos julgamentos (Hammond et al., 1998). Sendo assim, a oitava questão proposta pela pesquisa é apresentada conforme segue:

Q8: Os preparadores das demonstrações contábeis que apresentam aversão à mudança tendem a apresentar maior viés nos seus julgamentos em relação a eventos contábeis?

\subsubsection{Complexidade da Tarefa}

A complexidade da tarefa pode ser definida como o quantitativo de atenção ou o processamento que determinada tarefa requer, bem como a estrutura e clareza que a ela fornece (Choi, Newman \& Tafkov, 2015). Para Chand et al. (2010), a complexidade de uma tarefa contábil aumenta o tempo gasto no esforço cognitivo aplicado na interpretação de uma norma. 
Conforme exposto no estudo de Libby e Tan (1994), o nível de complexidade pode ser definido de duas formas: tarefas estruturadas, que representam as menos complexas; e as tarefas não estruturadas, que representam as mais complexas. Executar tarefas rotineiras ou familiares representa realizar tarefas "estruturadas", pois o procedimento é bem estabelecido e pode ser seguido por uma resposta objetiva (Chand et al., 2010).

Libby e Tan (1994) comentam que em uma tarefa bem estruturada o problema a ser resolvido é bem definido e as soluções alternativas e informações relevantes bem especificadas, não sendo necessários muitos cálculos e aplicação de raciocínio. Já as tarefas não estruturadas podem não ter respostas objetivamente corretas, fornecem menos orientação e são geralmente mais complexas (Chand et al., 2010). Em tarefas altamente complexas, é necessário unir um conjunto de estratégias para tomar uma decisão.

Especificamente, quando um padrão contábil é baseado em princípios, este é mais complexo. Sendo assim, o preparador das demonstrações contábeis precisará interpretar expressões de incerteza e avaliar vários princípios gerais na determinação da divulgação financeira (Chand et al., 2010). Assim, considerando que os padrões contábeis emitidos pelo IASB sejam mais "complexos", a quantidade de informações que os profissionais devem avaliar é maior (Chand et al., 2010).

Ishaque (2020) comenta que quanto maior a dificuldade percebida pelos profissionais ao executar uma tarefa, menor a probabilidade de executá-la corretamente, porém, no estudo desenvolvido por Rasso (2015), foi identificado que as tarefas mais complexas podem induzir maior ação cética do profissional, pois um maior foco é exigido pelo grau da dificuldade da tarefa, demandando um maior esforço cognitivo do profissional. Assim, com o maior esforço cognitivo, o indivíduo utiliza o sistema 2 para realizar seus julgamentos, sendo mais reflexivo e reduzindo o viés na tomada de decisão (Rasso, 2015).

Assim, mediante o exposto, como as normas internacionais de contabilidade emitidas pelo IASB são baseadas em princípios, elas contêm expressões de incerteza que tornam a tarefa de julgamento e tomada de decisão mais complexa. Por conta disso, as questões relacionadas ao nono aspecto discutido nesta pesquisa são apresentadas conforme segue:

Q9a: Os preparadores das demonstrações contábeis que recebem uma tarefa mais complexa tendem a apresentar menor viés nos seus julgamentos em relação a eventos contábeis?

Q9b: Os preparadores das demonstrações contábeis que recebem uma tarefa menos complexa tendem a apresentar maior viés nos seus julgamentos em relação a eventos contábeis?

\section{DISCUSSÃO DOS EFEITOS COGNITIVOS NOS JULGAMENTOS COM BASE NA INCERTEZA}

Os efeitos cognitivos apresentados neste ensaio podem distorcer os julgamentos. Cada aspecto comportamental apresentado pode causar julgamentos distintos para diferentes usuários, porque estes carregam consigo aspectos intrínsecos ou porque a informação contábil é apresentada de forma distinta.

Impulsividade e reflexividade são características naturais do indivíduo e a forma como este processa as informações recebidas pode distorcer seus julgamentos, gerando um viés que pode causar uma má tomada de decisão. Conforme abordado em estudos anteriores, espera-se que profissionais impulsivos apresentem maior viés, pois tendem a analisar menos as informações disponíveis, enquanto profissionais mais reflexivos podem ter menor viés, visto que seu poder de análise é mais crítico, ocasionando maior aproximação do resultado desejado pelo evento.

O ceticismo profissional também é compreendido como uma característica. Conforme apresentado, espera-se que um profissional mais cético gere um julgamento mais fidedigno, pois o ceticismo é compreendido como o poder de avaliação crítica ele possui, apresentando maior cautela na análise das informações para a formulação do julgamento. Entende-se que há relação 
do ceticismo profissional com a reflexividade do indivíduo, pois ambos os aspectos comportamentais estão relacionados ao poder de análise crítica para a formulação de melhores julgamentos.

O otimismo ou pessimismo é um aspecto natural do comportamento humano e o julgamento ideal é aquele considerado neutro, ou seja, sem viés de seleção. Assim, indivíduos que se apresentam como otimistas ou pessimistas são considerados como aqueles que apresentam julgamentos enviesados, distorcendo assim os resultados apresentados e a consequente tomada de decisões. Como os julgamentos em contabilidade são relacionados a eventos que influenciam os resultados, espera-se que indivíduos otimistas realizem escolhas que superestimam os resultados, enquanto os indivíduos pessimistas realizem escolhas que subestimam esses resultados, ambos apresentando julgamentos que não representam a realidade do evento.

A familiaridade do indivíduo com o processo de julgamento é considerada um aspecto natural. Sendo assim, conforme apresentado, ela pode gerar um efeito positivo ou negativo no julgamento profissional, cabendo maior investigação. Espera-se que a familiaridade do profissional com um evento possa ter efeito positivo no julgamento, pois ele tem mais conhecimento do procedimento correto para realizar a melhor estimativa, porém esse aspecto também pode ter efeito negativo, pois, se o indivíduo considerar esse evento familiar, pode ser impulsivo ao realizar o julgamento, reduzindo assim a qualidade da informação. Portanto, a familiaridade possui alguma relação com a impulsividade e reflexividade.

Outro aspecto que pode influenciar os julgamentos desses usuários é o tipo de informação que eles possuem, e se essas informações passadas influenciam ou não os seus julgamentos. Espera-se que práticas passadas dos usuários possam distorcer os seus julgamentos e que a impulsividade e reflexividade possam mitigar o efeito dessas informações passadas (âncoras) nos julgamentos dos preparadores. O ceticismo profissional também pode mitigar o efeito, ou seja, quanto mais cético o profissional, menos âncoras ele pode utilizar.

O excesso de confiança é outro efeito natural do indivíduo na realização de seus julgamentos de eventos. Indivíduos altamente confiantes tendem a confiar fortemente em seus julgamentos e informações adicionais sobre esses eventos podem não surtir efeito na sua decisão. Assim, espera-se que alguém com excesso de confiança tenha julgamentos enviesados. Entendese que esse aspecto tenha relação com a impulsividade e que esses indivíduos não sejam céticos em suas decisões.

A aversão à perda e à mudança são duas características relacionadas entre si e consideradas aspectos naturais das pessoas. Espera-se que indivíduos que tenham aversão a perdas distorçam seus julgamentos, sempre optando por não arriscar em operações, mesmo que atrativas, e, por conta disso, apresentam aversão à mudança, sempre optando por manter-se com a mesma opção, por medo de arriscarem. Assim, ao lidar com eventos futuros, baseados em expressões de incerteza, indivíduos avessos à perda e à mudança, ao estimar eventos futuros que podem diminuir resultados, podem realizar julgamentos não fidedignos. Podem-se considerar pessimistas os usuários que apresentem essas características, conforme já discutido anteriormente.

O último aspecto discutido faz referência à complexidade que a tarefa contábil, ou seja, à forma como a informação é fornecida ao preparador. Espera-se que ela, se estruturada ou não, possa influenciar nos julgamentos dos usuários. Quando a informação é complexa, o indivíduo pode ter que refletir mais sobre a questão, perdendo sua impulsividade (caso a apresente naturalmente). No entanto, em tarefas menos complexas, o indivíduo procede a seus julgamentos de forma mais impulsiva, até pela familiaridade deste com a tarefa, o que pode distorcer seus julgamentos.

Entende-se, portanto, que os aspectos apresentados podem influenciar julgamentos que os preparadores das demonstrações realizam. Também, percebe-se que em vários momentos os efeitos cognitivos apresentados se relacionam, podendo moderar o efeito de uns em outros e 
ajudando a melhorar (ou não) os julgamentos realizados com base em expressões de incerteza por parte dos preparadores contábeis.

\section{CONSIDERAÇÕES FINAIS}

Os julgamentos e decisões realizados pelos indivíduos no âmbito corporativo necessitam de informações contábeis e esses profissionais são denominados usuários dessas informações. Os mais diversos usuários das demonstrações fazem julgamentos sobre resultados futuros, ou seja, os julgamentos realizados por eles tendem a tomar a forma de previsões sobre um evento futuro incerto.

Assim, dada a importância da informação contábil para os seus diversos usuários, houve um esforço por parte dos normatizadores em adotar um sistema de relatórios financeiros baseado em princípios, atribuindo maior poder de julgamento aos profissionais da contabilidade. O IASB é responsável por emitir normas IFRS baseadas em princípios. Porém essas normas denotam expressões de incerteza, geralmente baseadas em eventos futuros da empresa.

Essas expressões de incerteza são utilizadas para expressar níveis de probabilidade de ocorrência de diversas transações retratadas pela contabilidade e a aplicação dessas normas exige um julgamento considerável dos preparadores das demonstrações contábeis, que são os responsáveis pelo reconhecimento, mensuração e divulgação dos eventos retratados pela contabilidade, ou seja, por atribuir a confiabilidade inicial das informações contábeis que serão utilizadas pelos auditores, gestores, investidores e demais usuários internos e externos $a$ posteriori (Clor-Proell \& Maines, 2014).

Porém essas expressões de incerteza no corpo das normas, por envolver julgamento considerável por parte dos preparadores, podem divergir, dependendo das características comportamentais envolvidas no processo. Esses julgamentos por vezes causam diferentes interpretações das mesmas expressões por parte dos diversos usuários, o que vem a prejudicar a credibilidade do processo de convergência contábil, impedindo a comparabilidade dos relatórios (Chand et al., 2012).

Por isso, conforme apontado pelo ASOBAT (AAA, 1966), para o desenvolvimento da teoria contábil, é necessário o estudo do impacto das medidas contábeis nas ações humanas, já que essas diferentes medidas têm o poder de influenciar o raciocínio dos tomadores de decisão (AAA, 1966). Nesse caso, este estudo teve o intuito de identificar e discutir os aspectos comportamentais que podem influenciar o processo de julgamento e tomada de decisão dos preparadores das demonstrações contábeis.

Foram identificados aspectos comportamentais que podem influenciar o processo de julgamento e tomada de decisão dos preparadores, mais especificamente, julgamentos baseados em expressões de incerteza, acerca de eventos futuros incertos. As expressões de incerteza são constantes nos padrões contábeis emitidos pelo IASB, por isso é importante entender quais efeitos essas informações podem ter sobre o comportamento dos usuários.

Os aspectos comportamentais discutidos neste ensaio teórico foram: impulsividade, ausência de ceticismo, otimismo natural e pessimismo, familiaridade, ancoragem, excesso de confiança, aversão à perda, aversão à mudança e complexidade da tarefa. Para todos esses efeitos cognitivos, foram elaboradas uma ou duas questões de pesquisa relacionadas ao aspecto. Esperase que cada aspecto discutido possa ser testado em estudos futuros.

Percebe-se, mediante as proposições apresentadas, que os julgamentos dos usuários podem ser influenciados de diversas formas e vários aspectos relacionados ao comportamento natural do indivíduo ou à forma como a informação é evidenciada podem fazer com que os julgamentos sejam melhorados ou não. Assim, este estudo visa contribuir para estudos que visem compreender o processo que permeia a tomada de decisão em contabilidade, contribuindo para o desenvolvimento da teoria contábil e integrando a psicologia comportamental para o melhor entendimento das decisões. 
Identificaram-se nove aspectos do comportamento humano, mesmo havendo outros fatores que podem influenciar o preparador das demonstrações contábeis em seus julgamentos. Assim, optar por discutir os efeitos cognitivos elencados neste estudo torna-se uma limitação. Sugere-se para estudos futuros que sejam discutidos outros aspectos comportamentais como influenciadores dos julgamentos dos contadores. Sugere-se também que esses aspectos elencados no corpo deste ensaio teórico sejam testados empiricamente.

\section{REFERÊNCIAS}

Almeida, M. D., Lemes, S., Weffort, E. F. J., \& Malaquias, R. F. (2009). Análise da percepção sobre expressões de incerteza presentes nas normas internacionais de contabilidade. Revista Contabilidade, Gestão e Governança, 11(1-2).

American Accounting Association [AAA]. (1966). A Statement of Basic Accounting Theory (ASOBAT). Florida: AAA, 1-100.

Bang, D., \& Frith, C. D. (2017). Making better decisions in groups. Royal Society open science, 4(8), 170193.

Barney, J. B. (2001). Resource-based theories of competitive advantage: A ten-year retrospective on the resource-based view. Journal of Management, 27(6), 643-650.

Bonner, S. E. (1999). Judgment and decision-making research in accounting. Accounting Horizons, 13(4), 385-398.

Brewster, B. E., Peecher, M. E., \& Solomon, I. (2015). What Improves Auditors' Assessments of the Risk of Intentional Misstatement? While Prompts to be Skeptical Can Hurt, Auditor Wisdom Helps. Working Paper.

Bruns, W. J. (1968). Accounting information and decision-making: some behavioral hypotheses. The Accounting Review, 43(3), 469-480.

Caplan, E. H. (1966). Behavioral assumptions of management accounting. The Accounting Review, 41(3), 496-509.

Chand, P., Cummings, L., \& Patel, C. (2012). The effect of accounting education and national culture on accounting judgments: A comparative study of Anglo-Celtic and Chinese culture. European Accounting Review, 21(1), 153-182.

Chand, P., Patel, C., \& Patel, A. (2010). Interpretation and application of "new" and "complex" international financial reporting standards in Fiji: Implications for convergence of accounting standards. Advances in Accounting, 26(2), 280-289.

Choi, J., Newman, A. H., \& Tafkov, I. D. (2015). A marathon, a series of sprints, or both? Tournament horizon and dynamic task complexity in multi-period settings. The Accounting Review, 91(5), 1391-1410.

Clor-Proell, S. M., \& Maines, L. A. (2014). The Impact of Recognition versus Disclosure on Financial Information. Journal of Accounting Research, 52(3), 671-701. 
Clor-Proell, S. M., \& Nelson, M. W. (2007). Accounting standards, implementation guidance, and example-based reasoning. Journal of Accounting Research, 45(4), 699-730.

Comitê de Pronunciamentos Contábeis [CPC] (2019). CPC 00 (R2): Estrutura Conceitual para Relatório Financeiro. Brasília, DF.

De Bondt, W. F., \& Thaler, R. H. (1995). Financial decision-making in markets and firms: A behavioral perspective. Handbooks in Operations Research and Management Science, 9, 385410 .

Doupnik, T. S., \& Riccio, E. L. (2006). The influence of conservatism and secrecy on the interpretation of verbal probability expressions in the Anglo and Latin cultural areas. The International Journal of Accounting, 41(3), 237-261.

Einhorn, H. J. (1976). A synthesis: Accounting and behavioral science. Journal of Accounting Research, 14, 196-206.

Feldman, G., Kutscher, L., \& Yay, T. (2020). Omission and commission in judgment and decision making: Linking action-inaction effects using the concept of normality. Social and Personality Psychology Compass.

Frederick, S. (2005). Cognitive reflection and decision making. Journal of Economic Perspectives, 19(4), 25-42.

Hammond, J. S., Keeney, R. L., \& Raiffa, H. (1998). The hidden traps in decision making. Harvard Business Review, 76(5), 47-58.

Han, Y., Chand, P., \& Mala, R. (2019). Impact of ambiguity tolerance and tertiary education on professional judgment. Accounting Forum, 426-447.

Ishaque, M. (2020). Cognitive approach to understand the impact of conflict of interests on accounting professionals' decision-making behaviour. Accounting Forum, 1-35.

Jelihovschi, A. P. G., Cardoso, R. L., \& Linhares, A. (2016). Look before you leap: the effectsof cognitive impulsiveness and reasoning process on rational decision making. Working Paper. Available at SSRN: https://ssrn.com/abstract=2912428

Kahneman, D., \& Tversky, A. (1973). On the psychology of prediction. Psychological Review, 80(4), 237.

Kahneman, D., Knetsch, J. L., \& Thaler, R. (1991). The Endowment Effect, Loss Aversion, and Status Quo Bias. Journal of Economic Perspectives, 5(1), 193-206.

Libby, R., \& Tan, H. T. (1994). Modeling the determinants of audit expertise. Accounting, Organizations and Society, 19(8), 701-716.

Meneghetti, F. K. (2011). O que é um ensaio-teórico? Revista de Administração Contemporânea, 15(2). 
Nolder, C., \& Kadous, K. (2015). The way forward on professional skepticism: Conceptualizing professional skepticism as an attitude. Suffolk University and Goizueta Business School at Emory University.

Perera, D., Chand, P., \& Mala, R. (2019). Confirmation bias in accounting judgments: the case for International Financial Reporting Standards for small and medium-sized enterprises. Accounting \& Finance.

Rasso, J. T. (2015). Construal instructions and professional skepticism in evaluating complex estimates. Accounting, Organizations and Society, 46, 44-55.

Reva, N. (2019). The Analogy in Decision-Making and the Implicit Association Bias Effect. Studia Humana, 8(2), 25-31.

Samuelson, W., \& Zeckhauser, R. (1988). Status quo bias in decision making. Journal of Risk and Uncertainty, 1(1), 7-59.

Sena, A. M. C. D. (2009). A theoretical essay on sustainability and environmentally balanced output growth: natural capital, constrained depletion of resources and pollution generation. Brazilian Administration Review, 6(3), 213-229.

Scheier, M. F., \& Carver, C. S. (1985). Optimism, coping, and health: assessment and implications of generalized outcome expectancies. Health Psychology, 4(3), 219.

Scheier, M. F., Carver, C. S., \& Bridges, M. W. (1994). Distinguishing optimism from neuroticism (and trait anxiety, self-mastery, and self-esteem): a reevaluation of the Life Orientation Test. Journal of Personality and Social Psychology, 67(6), 1063.

Scott, J., Stumpp, M., \& Xu, P. (2003). Overconfidence bias in international stock prices. Journal of Portfolio Management, 29(2), 80-89.

Tom, S. M., Fox, C. R., Trepel, C., \& Poldrack, R. A. (2007). The neural basis of loss aversion in decision-making under risk. Science, 315(5811), 515-518.

Trotman, K. T., Tan, H. C., \& Ang, N. (2011). Fifty-year overview of judgment and decision-making research in accounting. Accounting \& Finance, 51(1), 278-360.

Tversky, A., \& Kahneman, D. (1973). Availability: A heuristic for judging frequency and probability. Cognitive Psychology, 5(2), 207-232.

Tversky, A., \& Kahneman, D. (1974). Judgment under uncertainty: Heuristics and biases. Science, 185(4157), 1124-1131.

Tversky, A., \& Kahneman, D. (1991). Loss aversion in risk less choice: A reference-dependent model. The Quarterly Journal of Economics, 106(4), 1039-1061.

Zhang, Y., Zoysa, A., \& Cortese, C. (2019). Uncertainty Expressions in Accounting: Critical Issues and Recommendations. Australasian Accounting Business \& Finance Journal, 13(4). 